\title{
O PROÊMIO DA GENEALOGIA DEORUM GENTILIUM DE GIOVANNI BOCCACCIO
}

\author{
Pedro Falleiros Heise \\ Universidade Federal de São Paulo
}

Resumo: Por volta de 1350, provavelmente logo após a conclusão da primeira redação do Decameron, Boccaccio recebeu a incumbência por parte de Hugo de Sanseverino, rei de Jerusalém e Chipre, de compor uma obra de grande fôlego: a Genealogia deorum gentilium. A obra compreende 15 livros, e nos dois últimos há a famosa defesa da poesia. A partir destes dois livros, vimos desenvolvendo um projeto de pesquisa de pós-doutorado para analisar a poética de Boccaccio. Um dos pontos do projeto prevê a tradução destes dois livros, à qual julgou-se conveniente acrescentar o proêmio da obra, uma vez que se trata da introdução geral do texto, conforme requeria a retórica na composição de tratados. Tendo em vista que se trata de texto inédito em língua portuguesa, propomos a tradução dos primeiros 40 parágrafos do proêmio desta ingente obra, a fim de que o público brasileiro possa entrar em contato com os escritos latinos de Boccaccio.

Palavras-chave: Boccaccio. Tradução. Proêmio. Genealogia dos deuses pagãos.

\section{Proêmio}

[1] Se bem entendi as palavras de Domnino de Parma, teu egrégio soldado, ínclito rei, desejas grandemente uma genealogia dos deuses pagãos e dos heróis que descendem deles, conforme as ficções dos antigos, e, com ela, aquilo que outrora os homens ilustres pensaram sob a cobertura das fábulas, e desejas, eleito por tua dignidade, como um homem muito experto e erudito em tais assuntos, que seja eu o autor de tal obra.

[2] Na verdade, para omitir a admiração que teu desejo causa, pois não é conveniente a um pequeno homem perscrutar o que move um rei, e para não mencionar o que penso em relação a minha eleição, nem para que penses que eu terei mostrado minha insuficiência

\section{c) (i) (9)}

Esta obra está licenciada sob uma Licença Creative Commons.

\footnotetext{
* Professor Adjunto de Língua e Literatura Latina da Escola de Filosofia, Letras e Ciências Humanas da Universidade Federal de São Paulo (EFLCH UNIFESP). Pós-doutor em Italianística pela Universidade de São Paulo (2012/2014 bolsista FAPESP), doutor em Italianística pela Università degli Studi di Roma Tor Vergata (2011 bolsista do Ateneo), mestre em Língua e Literatura Italiana (2007 bolsista CNPq) pela Faculdade de Filosofia, Letras e Ciências Humanas da Universidade de São Paulo (FFLCH USP) e bacharel em Letras Português-Italiano (2004 bolsista CNPq) pela mesma instituição. Atualmente é membro do grupo de pesquisa "República das Letras" da USP. Tem experiência na área de Letras, com ênfase em língua e literatura latina, italiana e brasileira, literatura comparada e tradução. E-mail: pedraofh@yahoo.com.
} 
através de subterfúgios evitando o peso do trabalho imposto, antes de eu chegar ao meu parecer sobre a obra imposta, eu gostaria de acrescentar, ó mais sereníssimo dos reis, senão todas ao menos uma parte das palavras que entre Domnino, teu insigne soldado, enquanto explicava as ordens de tua dignidade, e mim trocamos, para que lidas estas vejas teu juízo sobre mim e meu temor de modo suficiente, quando eu alcançar a obediência de tua majestade.

[3] Assim, quando ele com sua eloquente boca explicou os estudos sagrados de sua majestade e os admiráveis atos da realeza, assim como alguns títulos insignes e gloriosos de teu nome com muitas palavras, acabou tentando se esforçar grandemente a me levar ao teu parecer, e não somente com uma única razão, mas muitas, algumas das quais, confesso, pareciam muito boas.

[4] Depois que ele calou, tive a oportunidade de responder, e assim eu disse:

"Talvez julgues, eloquente soldado, ou teu rei, que em breve será nosso se Deus quiser, que essa loucura dos antigos, que sem dúvida tinham o desejo de serem considerados descendentes de sangue divino, ocupava um módico pedaço de terra, e tão ridículo, como era, que perseverasse pouco tempo e ainda pudesse reunir informações sobre isso facilmente como se fosse um trabalho muito recente?

[5] Entretanto, serei sempre educado: é bem diferente disso! Pois para que eu omita as Cicladas e as demais ilhas do mar Egeu, Acaia e Ilíria e Trácia, onde numa grande extensão os gravetos desta louca chama ardiam, especialmente quando florescia a república dos gregos, esta contaminação infectou o litoral dos mares eleuses, dos helespontanos, meônicos, ícaros, panfílios, cilícios, fenícios, sírios e egípcios. Nem Chipre de nosso rei, insigne honra, desta mancha ficou imune.

[6] Assim infectou todo o litoral da Líbia, da Sírtia, da Numídia e dos Atlantíacos e caiu na enseada do mar e nos remotíssimos jardins da Espéride. Nem apenas ao litoral do mar Mediterrâneo se conteve. Na verdade, penetrou também nas nações que não conheciam o mar. [7] Pois todos os habitantes caíram nesta ruína ao longo do litoral do Nilo que é carente de nascente: as areias líbicas juntamente com suas calamidades, as solidões dos antiquíssimos tebanos, assim como o alto Egito, e dos garamantes férvidos e quentes, os etíopes excessivamente peludos, os árabes cheirosos, os persas ricos, os povos gangárides, os hindus insignes pela negritude, os babiloneses e o excelso topo dos Cáucasos, cujos penhascos acidentados olham tanto para o férvido sol quanto para os gélidos vales, o mar cáspio e os selvagens hircânios, e todos os tanais, e os Ródopes sempre nevosos e também os países 
incultos dos Cítaros. [8] E depois de infectar as ondas do oceano oriental e as ilhas do mar Vermelho, por fim chegou até nós na Itália, e assim até mesmo Roma, senhora do mundo, foi ofuscada pela caligem desta nuvem.

[9] Para não divagar por todas as regiões em que esta ignorância penetrou, como podes ver facilmente, houve apenas uma pequena porção do mundo entre os triões e onde o sol se põe que não foi nobilitada com a progênie deste tipo de divindade, embora, como as demais, fora infectada pela nefanda credulidade.

[10] E estas coisas não aconteceram na nossa época. Talvez Abraão era um adolescente quando ela começou a se propagar entre os siciônios e a penetrar nas mentes dos homens ignorantes; iniciou a efervescer durante o período dos heróis e alcançou o máximo da honra e da fama, e perseverou até os dias da destruição da soberba Troia. Pois lembramos de ter lido que na guerra de Troia alguns filhos de deuses caíram, e Hécuba foi transformada em cadela e Polidoro em virgulta.

[11] Este foi um tempo antiquíssimo de muitos séculos atrás. E não há dúvidas que, por todos os lugares em que esta estultícia floresceu, aí mesmo foram escritos ingentes volumes, para que chegasse aos pósteros a divina nobreza dos antepassados através de monumentos literários. [12] E embora eu nunca tenha pensado que destes tais o número fosse pequeno, pois que foi enorme, Paulo Perusino, homem sério e o mais hábil e preocupado investigador de tais coisas, afirmou alguma vez, estando eu presente, que soube de Barlaam, um calabrês erudito sobretudo nas letras gregas, que não houve nenhum homem insigne, por sua importante posição ou por outra proeminência, em toda a Grécia, nas ilhas e nos litorais antes mencionados, naquele tempo, em que floresceu esta tolice, que não demonstrou ter sua origem de algum dos deuses.

[13] Então o que poderei dizer, ou tu, contemplando um mal tão antigo e que se difundiu por tantas partes, que perseverou por tantos séculos, explicado em tantos volumes e extendido a um tão grande número de homens? Acreditas que eu possa realizar os desejos de um rei? [14] Com efeito, se os montes oferecem passagens fáceis e os desertos impenetráveis um caminho aberto e conhecido, se os rios rasos e as tranquilas ondas dos mares, e para aquele que faz uma travessia Eolo mande desde seu antro ventos tão fortes quanto favoráveis, e, mais ainda, que qualquer homem que tenha seus pés atados aos dourados tornozelos de Argifonte e segundo seu desejo voe para onde quiser, dificilmente poderia percorrer tão amplas extensões de terra e de mar, ainda que ele vivesse o máximo possível de anos e não fizesse mais nada. 
[15] Concederei mais ainda; se a alguém for dada a possibilidade de alcançar todos esses lugares ao mesmo tempo e, com o favor da divina graça, as notícias das características e dos idiomas das várias nações, e se lhe dessem inteiros volumes; que mortal, sem contar comigo, será aquele que tenha forças tão sólidas, engenho tão perspicaz e memória tão tenaz, para ver tudo que estivesse perto, e entender as visões e conservar o que entendeu, e, por fim, escrevê-las com a pena e reuni-las numa obra?

[16] Acrescentavas ainda que eu deveria explicar aquilo que sob a sutil cobertura das fábulas haviam escondido os homens sábios, como se o ínclito rei pensasse que é estulto crer que os homens, eruditos em quase todas doutrinas, simplesmente descrevendo fábulas que não são consoantes com a verdade e que não têm outro significado senão o literal, teriam perdido tempo e derramado suores.

[17] Não nego, agradou-me esta discrição real e o argumento mais certeiro que me ofereceu foi que ele, como dizias antes, possui um engenho divino, e me incitou a cumprir seu desejo, desde que eu tenha as forças suficientes para isto.

[18] As explicações deste tipo são certamente mais difíceis do que julgas e são trabalho próprio de um teólogo; pois, embora de acordo com a opinião de Varrão, quando descreveu muito Sobre as coisas divinas e humanas, seja próprio da teologia este gênero, que é chamado mítico, ou, como outros preferem chamar, e quiçá melhor, físico, ainda que tenha muito de falsidade risível, não obstante requer muita técnica para eliminá-la. [19] Por isto, soldado mui distinto, as forças dos homens devem ser ponderadas e os engenhos examinados, e assim lhes serão impostos os pesos convenientes. Atlas pôde sustentar sobre sua cabeça o céu, e Alcides pôde substituí-lo quando estava cansado sob o peso, ambos homens divinos, e ambos tiveram um vigor quase invencível. [20] Mas o que tenho eu a ver com isso? Sou um pequeno homem, sem nenhuma força, de engenho lento e memória fluida; e tu desejas acrescentar sobre meus ombros, não direi o céu, que aqueles sustentaram, mas a terra e os mares, e ainda os próprios celícolas, e com eles também os egrégios homens que os sustentaram. [21] Isto não é outra coisa senão querer que eu seja comprimido pelo peso e morra.

Mas se apenas isto era o que estava na mente do rei, era o peso adequado, se entre os mortais há algum que tenha a capacidade para tamanho trabalho, para as forças do famosíssimo Francisco Petrarca, de quem sou discípulo já faz tempo. Este homem de fato é dotado de um engenho celeste e de memória perene, e ainda uma eloquência admirável, a 
quem são muito familiares as histórias de qualquer povo, conhecidíssimos os sentidos das fábulas, e, em suma, conhece qualquer coisa que jaz no seio da filosofia".

[22] Eu já me calara, quando ele com rosto plácido e com discurso bem composto continuou:

"Creio, muito mais do que eu podia ter sabido, que contas a verdade, e vejo as dificuldades; mas pergunto, meu caro João, acaso julgas que nosso rei carece de circunspeção? Meu senhor é clarividente e de engenho brando, e louvável por sua régia bondade. E longe dele querer oprimir alguém, muito menos a ti, mas antes tem por costume antigo aliviar dos pesos qualquer pessoa, e por isto sem dúvida devem ser compreendidas e aceitas suas ordens.

[23] Por Pólux, é fácil acreditar que são inacessíveis aquelas nações, que mencionaste antes, e que seus escritos, se existiram, são totalmente desconhecidos dos latinos; na verdade, ele deseja que tu investigues as coisas dos gregos que tenham chegado aos latinos, ou algo dos próprios latinos, que com suas letras não pouca honra e glória trouxeram os estudos dos antepassados, e se não podes encontrar todas, então deseja que pelo menos investigues aquelas que podem estar sob teu cuidado. [24] Sus então, com espírito generoso, esperando o bem de Deus, submete-te ao trabalho, e faça-o porque podes, pois ninguém te pede algo impossível. Nunca tive a boa sorte de encontrar esse homem sublime e conhecido por sua fama não só entre os cipriotas, mas também acima do céu, Francisco Petrarca, querendo assim Deus, como creio, para que eu poupasse aquele homem extremamente ocupado, e apresentasse à tua juventude um trabalho honesto, pelo qual teu nome, que há pouco tempo começou a subir aos céus, brilhe entre nós com ínclita glória e fama”.

[25] Então eu digo:

“Já vejo o suficiente, valoroso soldado, pois, omitindo os antiquíssimos livros dos bárbaros, julgas que é possível realizar uma obra integramente a partir dos gregos e dos latinos. Ó bom Deus! Não vês tu mesmo, Domnino, que com esta concessão eliminas a maior parte da obra? [26] Mas façamos como já fizeram há muito tempo os nossos chefes, dividindo o império romano em oriente e ocidente; este monstro tem dois corpos, um bárbaro e o restante grego e latino, e os livros que mencionas tratam dos gregos e dos latinos. [27] Nem mesmo isto seria possível para o que pedes; pois já demonstramos esta antiga peste. Tu agora pensa quantos livros tiveram inimigos ao longo dos tempos. Deverás admitir igualmente que os incêndios e os dilúvios, para não mencionar as particularidades, destruíram várias bibliotecas; e ainda que perecesse apenas a de Alexandria, que há muito tempo Filadelfo criou 
com tanta diligência, os livros seriam extremamente poucos, pois segundo o testemunho dos antigos podias encontrar nela o que quisesses.

[28] Além disso, fortificando-se o gloriosíssimo nome de Cristo, afastando com sua doutrina resplandecente de verdade sincera as trevas do erro mortal e sobretudo dos pagãos, e o brilho dos gregos já estava em declínio havia muito tempo, e os mensageiros de Cristo clamando contra a infausta religião e lançando-a ao extermínio, não é de se duvidar que destruíram muitos livros repletíssimos desta matéria, quando mostraram, com pregação tão verdadeira quanto pia, que não havia muitos deuses, nem filhos de deuses, mas um único Deus pai e um único filho de Deus.

[29] Ademais, admites que a avareza, cujas forças não são pequenas, também era uma inimiga; pois a capacidade poética certamente não traz nenhum lucro aos versados nela, e para a avareza nada é precioso a não ser que traga ouro. Consequência disto é que aquilo que não trazia ouro não só foi abandonado, mas também desprezado e descartado; e como quase todos voltam-se para a riqueza com todos seus pés, tais livros caíram em desuso, e assim também desapareceram facilmente. [30] Do mesmo modo, para o detrimento deles veio o ódio detestável de alguns chefes, e conspiraram contra eles como se fossem inimigos. E nenhum número poderia expressar facilmente quantos livros não só de fábulas mas de qualquer outra arte foram destruídos por este ódio. [31] Além disto, nem mesmo se alguns fossem preservados resistiriam, pois, carentes de restaurador, o correr do tempo, cujos dentes são silenciosos e de diamantes que corroem não só os livros, mas as mais duras rochas e o próprio ferro, acabaria com os demais. [32] O tempo, por Hércules, transformou em poeira muitos volumes tanto gregos como latinos!

Ainda que estes e muitos outros tenham sofrido, e sobretudo aqueles que seriam adequados para o nosso trabalho, não se pode negar que muitos sobreviveram, mas nenhum dos que eu conheço trata do tema que escolheste. Vagam, portanto, dispersos pelo mundo as nações e os nomes tanto dos deuses quanto dos progenitores. [33] Assim um livro traz algo do assunto, e outro livro outro tanto. Quem, então, pergunto, quereria procurá-los para um trabalho de pouca consideração, ou pelo menos pouco frutuoso, e folhear tantos volumes, lêlos e tirar tão pouco deles? Creio que seria melhor desistir disto".

[34] Mas ele, com seus olhos fixos em mim, disse: "Não me estava oculto que terias algo a dizer contra meu modesto pedido; porém não me recusarás até o ponto que não me sobre nenhum canto como meu refúgio. Certamente não negarei o que asseveras. Eu já queria dizer pela segunda vez: já que podes, faça-o! [35] Esta pequena porção do que podes obter 
daqui e dali é o que deseja nosso rei. Poderias recusar até isto? Mas ai! Temo que uma languidez preguiçosa te dê esses argumentos para escapares ao trabalho. Certamente nada é mais infame que um jovem ocioso. Mas como se deve trabalhar, pois todos nascemos para o trabalho, a quem melhor do que um excelente rei podes dedicar o trabalho? [36] Levanta-te, então, e repele esta inércia, e prepara o espírito para esta ingente obra, para que ao mesmo tempo obedeças ao rei e construas um caminho para teu nome até a gloriosa fama! Chegarás mais adiante, se fores prudente, do que aonde tento te impelir. Pois sabes que um grande trabalho vence tudo, e que a fortuna ajuda os audaciosos, e muito mais o próprio Deus, que nunca abandona os que têm esperança nele. [37] Então vamos, e com bons auspícios experimenta folhear e folhear os livros, agarra a pena, e, enquanto agradas ao rei, conduze teu nome para uma vida longuíssima!”

[38] Então eu:

"Vencido, digo, antes pela elegância das palavras que pela força da argumentação; uma vez que me incitas, me empurras e arrastas, deverei obedecer, queira ou não queira".

[39] E assim, rei clementíssimo, Domnino e eu discutimos por algum tempo, para que eu em algum momento dirija minha pena a ti; e, seja eu capaz ou não, vencido, chego por fim incitado a tua decisão; entretanto, vês com que forças. [40] Portanto, por tua ordem, abandonando os montes em caracol de Certaldo e o solo estéril, e com uma barca, ainda que pequena, descerei ao vertiginoso mar cheio de rochas cerradas como um novo marinheiro, sem saber que preço pagarei pelo trabalho de ter lido todos os livros; percorrerei a pé os litorais e as florestas montanhosas, as covas e os antros, se necessário, descerei até o inferno, e, convertido em outro Dédalus, voarei pelos ares; e por teu desejo, como se eu recolhesse pela vasta praia os fragmentos esparsos de um grande naufrágio, assim recolherei, num número quase infinito de livros, as relíquias dos deuses dos pagãos que eu conseguir encontrar; e as colocarei juntas segundo a ordem que puder, no contexto unitário de uma genealogia, por mais que estejam reduzidas e corrompidas e quase consumidas, para que tu possas satisfazer teu desejo.

\section{Texto original:}

\section{Prohemium}

[1] Si satis ex relatis Domnini Parmensis egregii militis tui vera percepi, Rex inclite, summopere cupis genealogiam deorum gentilium et heroum ex eis iuxta fictiones veterum 
descendentium, atque cum hac quid sub fabularum tegmine illustres quondam senserint viri, et me a celsitudine tua, quasi expertissimum atque eruditissimum hominem in talibus, selectum tanto operi autorem.

[2] Sane ut omiserim desiderii tui admirationem, non enim parvum hominem decet, quid regem moveat perscrutari, et adversus electionem mei quid sentiam dicere pretermictam, nedum insufficentiam meam monstravero per subterfugia arbitreris impositi laboris onus evitem, antequam ad sententiam meam circa impositum opus deveniam, libet, serenissime regum, apponere, etsi non omnia, quedam saltem que inter Domninum insignem militem tuum, dum iussa tue celsitudinis explicaret, et me intervenere verba, ut eis perlectis satis de me iudicium tuum videas et temeritatem meam, dum in obedientiam tue maiestatis devenio.

[3] Cum igitur ille facundo ore sacra tue sublimitatis studia et opera regalis officii admiranda nec non et insignes atque gloriosos quosdam tui nominis titulos longa dicacitate explicuisset, eo devenit ut conatu plurimo me in tuam sententiam ducere niteretur, nec unica tantum ratione sed multis ex quibus, fateor, valide videbantur quedam.

[4] Verum postquam tacuit et michi respondendi copia facta est, sic dixi:

“Arbitraris forsan, facunde miles, seu rex tuus de proximo noster futurus, prestante Deo, hanc insaniam veterum, scilicet cupientium se haberi divino procreatos sanguine, angulum terre modicum occupasse et tanquam ridiculum quoddam, ut erat, parvo perseverasse temporis tractu et veluti etiam recentissimum opus facile colligi posse?

[5] Attamen bona semper tua pace dicam: longe aliter est. Nam, ut omictam Cicladas et reliquas Egei maris insulas, Achaiam et Ylliricum atque Traciam, quas penes fomenta huius stultitie emicuere plurimum, et potissime dum Grecorum respublica floruit, Eleuxini maris, Hellespontiaci, Meonii, Ycarei, Pamphylii, Cilicii, Phenicis et Syri atque Egyptiaci litora sua contagione infecit. Nec Cyprus nostri regis insigne decus ab hac labe fuit immunis.

[6] Sic et omnem Lybie atque Syrtium et Numidie oram labefactavit et Athlantiacos occiduique maris sinus et remotissimos Hesperidum ortos. Nec Mediterranei tantum maris fuit contenta litoribus; quin imo et ad incognitas mari nationes etiam penetravit. [7] Decidere enim in perniciem hanc cum litoralibus accole omnes Nyli, fonte carentis, et harene lybice una cum suis pestibus, et antiquissimarum Thebarum solitudines, nec non et superiores Egyptii, atque Garamantes fervidi et calentes nimium hirsutique Ethyopes, et odori Arabes Perseque dites atque Gangarides populi et nigredine insignes Yndi, Babilones et celsa Caucasi cacumina, eiusque tam in fervidum solem quam in gelidas arthos scabrosa declivia, Caspium mare Hyrcanique truces et omnis Tanais ac nivosus semper Rhodopes et Scytharum etiam inculta 
barbaries. [8] Et cum orientalis occeani fluctus et Rubri maris infecisset insulas, postremo ad nos usque Ytalos declinavit, adeo ut Roma, rerum domina, huius caliginis offuscata nube sit.

[9] Et ne passim per regiones omnes, in quibus plurimum hec inscitia potuit, evager, ut satis potes advertere, portiuncula sola fuit orbis inter triones et cadentem solem, que deitatis huius modi non fuit nobilitata progenie, esto nephande credulitatis sicuti et reliqua fuerit infecta.

[10] Nec ista evo fuere nostro. Erat forsan adhuc adolescens Abraham dum apud Sicyonios cepit ista proserpere et insipientium hominum subintrare animos; heroum tamen tempestate ferbuit et in maximum devenit decus et nomen, et in dies usque superbi Ylionis ruine perseveravit. Nam in Troiano bello quosdam deorum filios cecidisse et Hecubam in canem et Polidorum in virgulta conversos legisse meminimus.

[11] Quod quidem et vetustissimum est et plurium seculorum tempus. Nec dubitandum insuper quin, quocunque hec viguerit stultitia, ibidem ingentia sint descripta volumina, ut maiorum divina nobilitas monimento licterarum veniret ad posteros. [12] Et esto nunquam existimaverim talium parvum fuisse numerum, quod permaximus fuerit, Paulus Perusinus, vir gravis et talium solertissimus atque curiosissimus exquisitor, non nunquam asseruit, me presente, se a Barlaam, quodam Calabro homine Grecarum licterarum apprime erudito, habuisse neminem insignem virum, principatu aut preminentia alia, tota in Grecia insulis et litoribus premonstratis, eo fuisse seculo, quo hec fatuitas viguit, qui ab aliquo deorum huius modi duxisse originem non monstraret.

[13] Quid igitur dicam, quid tu, spectantes tam longe lateque diffusum malum tam vetus, tot perseveratum seculis, tot explicatum voluminibus et in tam grandi virorum numero ampliatum? Credisne me regis optata posse perficere? [14] Equidem si prestent montes faciles transitus et solitudines invie apertum notumque iter, si flumina vada et maria tranquillas undas, ac transfretanti emictat ab antro Eolus ventos tam validos quam secundos, et, quod maius est, sint Argiphontis talaria aurea volucri cuicunque homini alligata pedibus, et pro votis, quocumque libuerit evolet, vix tam longos terrarum marisque tractus, etiam si illi prestetur permaxima seculorum annositas, nedum aliud agat, solum poterit peragrasse.

[15] Concedam amplius; detur cui velis hec omnia posse contingere in momento loca et, divina insuper favente gratia, caractherum ac ydiomatum variarum nationum notitia, et coram accedenti integra preparentur volumina; quis, ut me pretermiserim, mortalium erit cui sint vires tam solide, tam perspicax ingenium tamque tenax memoria, ut omnia videre queat 
apposita, et intelligere visa et intellecta servare, et demum calamo etiam exarare et in opus collecta deducere?

[16] Addebas preterea ut explicarem quid sub ridiculo cortice fabularum abscondissent prudentes viri, quasi rex inclitus arbitretur stolidum credere homines, fere omni dogmate eruditos, simpliciter circa describendas fabulas nulli veritati consonas nec preter licteralem sensum habentes, trivisse tempus et inpendisse sudores.

[17] Non inficiar, delectavit me regalis ista discretio et argumentum certissimum prebuit quoniam, ut tu ante dicebas, sit illi divinum ingenium, meque in votum inpulit suum, dum modo vires sufficerent.

[18] Sane circa huiusmodi explicationes longe plus quam putes difficultatis et theologi hominis labor est; nam, dato, iuxta Varronis sententiam, ubi De divinis et humanis rebus multa descripsit, genus hoc theologie sit, quod mithicon, seu, ut aliis placet et forte melius, physicon dicitur, etsi plurimum ridende falsitatis habeat, multum tamen ad illam eliciendam artis exquirit. [19] Et ob id, miles elegantissime, pensande sunt hominum vires et examinanda ingenia, et sic illis convenientia onera imponenda. Potuit Athlas sustinere capite celum, eique fesso sub onere Alcides potuit prestare vicem, divini homines ambo, et invictum fere robur fuit ambobus. [20] Ast ego quid? Brevis sum homuncio, nulle michi vires, ingenium tardum et fluxa memoria; et tu meis humeris, non dicam celum, quod illi tulere, quin imo et terram super addere cupis et maria, ac etiam celicolas ipsos, et cum eis sustentatores egregios. [21] Nil aliud hoc est nisi velle ut pondere premar et peream.

Verum si tantum regi hoc erat animo, erat onus aptum, si inter mortales ullus est tanto labori sufficiens, viribus preclarissimi viri Francisci Petrarce, cuius ego iam diu auditor sum. Homo quippe est celesti ingenio preditus et perenni memoria, ac etiam facundia admirabili, cui familiarissime quarumcunque gentium hystorie sunt, sensus fabularum notissimi, et breviter quicquid phylosophie sacro iacet in gremio, manifestum est”.

[22] Tacueram iam, cum sic ille vultu placido et comto sermone secutus est:

"Credo, longe melius quam noverim, ea vera esse, que narras, et difficultates video; sed queso, mi Iohannes, an putes regem nostrum circumspectione carere? Oculatus quippe dominus est et mitis ingenii, et regia facilitate laudabilis. Et absit ut quenquam, nedum te, premere velit, quin imo vetus est illi mos leviare quoscunque, et idcirco sane intelligenda atque assumenda iussa ipsius.

[23] Edepol facile credi potest inaccessibiles esse eas, quas predixeras, nationes et eorum codices, si qui sunt, omnino Latinis incognitos; verum, si qua ex Grecis, que ad Latinos 
usque devenerint, seu apud Latinos ipsos, quorum licteris non parum honoris et glorie maiorum attulere studia, comperiantur, etsi non omnia, que saltem tua cura haberi possint, ista desiderat. [24] Eia ergo, liberali animo, bene de Deo sperans, laborem subi, et quod potes facito, cum ad impossibile requiratur nemo. Non enim michi virum illum sublimem et, nedum apud Cyprios, sed fama super ethera notum, Franciscum Petrarcam dedit fortuna obvium, credo sic volente Deo, ut et illi maximis occupato parcerem, et iuventuti tue honestum laborem inferrem, ex quo nomen tuum, nuper in auras exire incipiens, inclita gloria elucescat clarius apud nostros".

[25] Tunc ego inquam:

"Iam satis video, strenue miles, quod, pretermissis barbarorum remotissimis libris, existimes ex Grecis Latinisque opus hoc integrum perfici posse. O bone Deus! Nonne ipse, Domnine, vides quia hac ipsa concessione maximam partem operi demas? [26] Sed faciamus uti iam dudum nostri fecere principes, Romanum imperium dividentes in orientale et occiduum; sint monstro huic corpora duo, barbaricum unum et Grecum atque Latinum reliquum, ad Grecum Latinumque, quos ipsemet nominas, libri. [27] Nec istud etiam poterit ut quod postulas consequatur; antiquam enim hanc pestem monstravimus. Tu nunc tecum volve quot labentibus seculis hostes habuere volumina. Confiteberis equidem quoniam et incendia et aquarum diluvia, ut de particularibus taceam, bibliothecas assumpserint plurimas; etsi non alia deperisset quam Alexandrina, quam iam dudum Phyladelphus summa cum diligentia fecerat, esset librorum diminutio maxima, cum in ea testimonio antiquorum poteras reperire quod velles.

[28] Preterea, invalescente gloriosissimo Christi nomine, eiusque doctrina sincere veritatis perlucida letiferi erroris et potissime gentilicii tenebras amovente, ac etiam iam diu Grecorum declinante fulgore, clamantibus in infaustam religionem Christi nuntiis ac eam in exterminium pellentibus, nulli dubitandum est quin secum multos deleverint libros huius materiei refertissimos, dum non multos esse deos, nec deorum filios, sed unicum Deum patrem et filium Dei unicum tam vera quam pia predicatione monstrarent.

[29] Insuper avaritiam, cui non parve sunt vires, concedes habuisse hostem; facultas enim poetica scientibus nil afferre lucri certissimum est, et apud eam nil preciosum est preter quod afferat aurum. Ex quo consecutum ut aurum non afferentia, non solum neglecta, sed despecta atque deiecta sint; et cum omnes fere in divitias totis tendant pedibus, volumina talia in desuetudinem abiere, et sic etiam periere facile. [30] Eque in eorum detrimentum quorundam principum detestabile accessit odium, nec aliter quam in hostes ab eis adversus ea 
conspiratum est. Et quot hoc deleverit odium non solum fabularum, sed quarumcunque facultatum volumina, non leviter exprimeretur numerus. [31] Ceterum si cetera pepercissent, non eis, restauratore carentibus, pepercisset labile tempus, cui et taciti et admamantini sunt dentes, nedum libros, sed saxa corrodentes durissima et ferrum ipsum, domans cetera. [32] Hoc hercle tam Greca quam Latina multa redegit in pulverem!

Etsi hec et alia plura passa sint, et ea potissime, que nostro labori oportuna essent, negari tamen non potest quin multa supersint, sed nullum tamen, quod ego noverim, in hoc, quod optas, conscriptum. Vaganter igitur tam deorum quam progenitorum nationes et nomina, huc illuc dispersa per orbem. [33] Habet enim liber hic ex his aliquid, et aliquid liber alter. Que quis, queso, pro minime, seu saltem parum fructuoso labore velit exquirere et tot volumina volvere, legere et hinc inde excerpere perpauca? Credo satius desistendum".

[34] Ast ille, in me defixis luminibus inquit: "Non me latebat quin adversum moderatam petitionem meam haberes quid diceres; sed non adeo me repelles quin loculus remaneat aliquis, in quem fugiam. Non equidem negabo quod asseris. Verum iam secundo dixisse velim: quod potes, facito! [35] Hanc portiunculam, quam hinc inde excerpsisse poteris, rex noster exoptat. Poterisne istud etiam denegasse? Sed heu! Timeo non has tibi torpor ignavus rationes preparet, ut laborem effugias. Nil nempe turpius ocioso iuvene. Etsi laborandum est, cum ad laborem nascamur omnes, cui melius quam regi optimo potes laborem inpendere? [36] Surge igitur, et inertiam hanc pelle, et ad opus ingenti accingere animo, ut regi pariter pareas et tuo nomini ad inclitam famam viam facias! Venies profecto, si prudens es, ultro eo quo ego te conor inpellere. Nosti enim quoniam labor improbus vincat omnia, audentesque iuvet fortuna, et multo magis Deus ipse nunquam deserens sperantes in se. [37] Vade igitur, et bonis avibus volve et revolve et exentera libros, calamum arripe, et, dum regi obsequeris, tuum nomen in longissimum deduc evum!"

[38] Tum ego:

"Vincor, inquam, magis fere lepiditate verborum quam viribus rationum; urges etenim, me inpellis, trahis, et ut paream, si nolim velim, necesse est".

[39] Et sic, clementissime Rex, ut ad te aliquando calamum flectam, aliquandiu altercati sumus, Domninus tuus et ego; et, seu valeam seu non valeam, ad ultimum victus in tuam sententiam inpulsus venio; quibus tamen viribus, tu vides. [40] Iussu igitur tuo, montanis Certaldi cocleis et sterili solo derelictis, tenui licet cymba in vertiginosum mare crebrisque implicitum scopulis novus descendam nauta, incertus nunquid opere precium facturus sim, si omnia legero; litora et montuosa etiam nemora, scrobes et antra, si opus sit, 
peragravero pedibus, ad inferos usque descendero, et, Dedalus alter factus, ad ethera transvolavero; undique in tuum desiderium, non aliter quam si per vastum litus ingentis naufragii fragmenta colligerem sparsas, per infinita fere volumina deorum gentilium reliquias colligam, quas comperiam, et collectas evo diminutas atque semesas et fere attritas in unum genealogie corpus, quo potero ordine, ut tuo fruaris voto, redigam.

\section{Referência}

BOCCACCIO, Giovanni. Genealogy of the pagan gods. Tradução e texto crítico editado por Jon Solomon. Cambridge: Harvard University Press, 2011.

[Recebido em fevereiro de 2014 e aceito para publicação em outubro de 2014]

\section{The Preface of the Genealogy of the pagan gods by Giovanni Boccaccio}

Abstract: Around 1350, probably after the conclusion of the first redaction of the Decameron, Boccaccio received the commission by Ugo of Sanseverino, king of Jerusalem and Cyprus, to compose a work of great effort: the Genealogia deorum gentilium. This work includes 15 books, and in the last two we find the famous defense of poetry. From this two books, we are developing a project in a postdoctoral research to analyze the poetic ideas of Boccaccio. One of the points of the project concerns the translation of these books, and we thought it would be convenient to add the preface of the work, since it is the general introduction of the text, as required by the rhetoric composition of treatises. Considering that it is a unpublished text in Portuguese, we propose the translation of the forty paragraphs of the preface of this enormous work, so that the Brazilian public can read some Latin passages of Boccaccio.

Keywords: Boccaccio. Translation. Preface. Genealogia deorum gentilium.

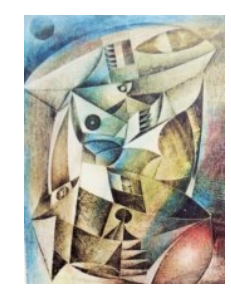

